Indexed by

\title{
Scopus
}

\section{STRATEGY OF WATER-FLOODING ENHANCEMENT FOR LOW-PERMEABLE POLYMICTIC RESERVOIRS}

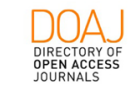

Crossref

$\mathrm{R} \partial \mathrm{AD}$

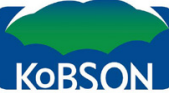

Aleksandra Palyanitsina

Saint Petersburg Mining

Univerity, Oil and Gas Faculty,

Development and Operation

Oil and Gas Fields,

Saint Petersburg, Russian

Federation

\section{Dmitry Tananykhin}

Saint Petersburg Mining

Univerity, Oil and Gas Faculty,

Development and Operation Oil

and Gas Fields,

Saint Petersburg, Russian

Federation

\section{Riazi Masoud}

Shiraz University,

School of Chemical and

Petroleum Engineering,

Fars, Iran

Key words: waterflooding, artificial waterflooding, reservoir pressure maintenance system, low-permeable reservoir, polymictic reservoir, Western Siberia, enhanced oil recovery, low-salinity waterflooding

\section{Cite article:}

Aleksandra, P., Dmitry, T., \& Riazi M. [2021]. Strategy of water-flooding enhancement for low-permeable polymictic reservoirs. Journal of Applied Engineering Science, 19(2), 307 - 317. DOI:10.5937/ jaes0-29693

Online aceess of full paper is available at: www.engineeringscience.rs/browse-issues 


\title{
STRATEGY OF WATER-FLOODING ENHANCEMENT FOR LOW-PERMEABLE POLYMICTIC RESERVOIRS
}

\author{
Aleksandra Palyanitsina ${ }^{1 *}$, Dmitry Tananykhin', Riazi Masoud ${ }^{2}$ \\ ${ }^{1}$ Saint Petersburg Mining Univerity, Oil and Gas Faculty, Development and Operation Oil and Gas Fields, \\ Saint Petersburg, Russian Federation \\ ${ }^{2}$ Shiraz University, School of Chemical and Petroleum Engineering, Fars, Iran
}

This article pays attention to the issues of increasing the efficiency of the development of oil fields with low-permeable polymictic reservoirs. It is possible to increase the efficiency of this process by improving the technology of their artificial water-flooding. This goal is being realized by identifying the features of the development of low-permeable polymictic reservoirs of fields in Western Siberia and creating a strategy to improve the technology of artificial waterflooding, taking into account the impact on the surface molecular properties of the reservoir system by the stages of their development. The developed strategy was substantiated in stages using hydrodynamic modeling. Also, an assessment was made of the effectiveness of the implementation of low-salinity waterflooding at the late stage of development of low-permeability polymictic reservoirs, the optimal time for changing the waterflooding agent from formation water to fresh water was determined.

Key words: waterflooding, artificial waterflooding, reservoir pressure maintenance system, low-permeable reservoir, polymictic reservoir, Western Siberia, enhanced oil recovery, low-salinity waterflooding

\section{INTRODUCTION}

At present, the world structure of hydrocarbon resources and reserves [1] looks in such a way that oil geologists are increasingly faced with such reservoir rocks, for which technologies widely recommended in the world practice of oil field development are technologically and economically unprofitable. However, the significant number of oil fields currently being developed with productive low-permeable polymictic reservoirs are characterized by the presence of objects that have not been put into development. At the same time, the prevalence of the geomechanical approach is traced in the existing trends [2] for improving the development systems of such fields, and there is practically no consideration of the impact on the surface molecular properties of reservoir systems when organizing waterflooding systems. In addition, an increase in the number of fields with residual oil in flooded formations is a feature of the near future. But the use of traditional waterflooding methods is characterized by the development of reservoirs, which are characterized by both low rates of production and low final oil recovery. Therefore, it is necessary to develop an optimal strategy for improving artificial waterflooding systems in fields with such reservoirs from the standpoint of physicochemical processes occurring when oil is displaced by water.

\section{LITERATURE REVIEW}

The design of the development of low-permeable polymictic reservoirs must be carried out taking into account their inherent features, due to their mineral composition and structure of the pore space, as well as manifested surface-molecular phenomena.

The pore space is represented by channels of small size, that is, capillary and sub-capillary pores, which create significant filtration resistance during the movement of fluids in a porous medium and capillary effects.

If we consider the mineral composition, then one of the key issues in the development of such reservoirs is the predominant content of fine fractions in rocks [3] and their poly mineral composition of both the rock-forming and cementing parts [4]. Particular attention is also paid to the high content of clay minerals in cement, which have specific features that significantly affect the technical indicators of field development. Consider them below.

- The first is the increase in clay volume due to liquid absorption. This increase depends on the structure of the crystal lattice of the clay and the composition of the liquid. In this case, the increased clay volume can both remain on the rock skeleton and be detached from it, leading to the dispersion of clays $[5,6]$.

- The second feature, which is especially relevant when considering clays as seals and reservoir replacement zones, is their high compressibility, i.e. the ability to change its volume under the influence of external loads, especially in the field of plastic deformations. Due to this feature, clay interlayers make significant adjustments to the piezoconductivity of the reservoir system, as well as to its filtration characteristics. These interlayers slow down the process of pressure redistribution and lead to an irreversible decrease in permeability with changes in the stressstrain state of the formation [5,7-8].

- Besides, clay minerals, due to their small size, have a large adsorption surface on which water molecules and exchangeable cations can be retained. In this case, the magnitude of the adsorption capacity 
is strongly related to the size of the specific surface area, which varies depending on the type of clay mineral. According to the results of experimental studies, it was found that the largest surface is characterized by montmorillonites (smectites), minerals capable of cleavage, and the smallest - kaolinite [9-11].

The structure of the pore space of low-permeability polymictic reservoirs causes deviations at low-pressure gradients from the linear Darcy filtration law. Earlier, this fact was revealed by several researchers during the filtration of liquid in clay deposits.

Recently published works [12-15] showed the results of laboratory studies of nonlinear effects, which revealed that such effects occur not only for oil but also for single-phase filtration of water, which is a Newtonian liquid. The noted effects have a significant impact on the processes occurring in the studied reservoirs with a permeability value of less than $10-15 \mathrm{~m}^{2}$. These experiments were carried out with filtration fluids in a low-permeable porous medium in reservoir conditions of productive deposits of the Priobskoye field. These effects are manifested in the form of a decrease in the oil recovery factor (ORF) or an increase in development time.

According to the previously presented geological features of the development of low-permeability polymictic reservoirs, the problem of organizing a reservoir pressure maintenance system (RPM) is traced. These problems are more typical when using various types of water as an injection agent since they are subject to higher requirements for their preparation. The requirements are determined by the influence of both the composition of the rock-forming and cementing part of the reservoir, and the structural features of the pore space [16]. The lack of thorough water treatment directly affects the injectivity of injection wells. And its decrease leads to a weakening of the effectiveness of both measures directly related to reservoir pressure maintenance and oil displacement by water, and the entire development system as a whole, which is manifested in low rates of oil withdrawal and current and final oil recovery factor [17].

In practice, the presented requirements are often not met, since the organization of the RPM system is mainly guided by old regulatory documents $[18,19]$. For example, in the Untygeyskoye field, where the content of suspended solid particles (SSP) in the injected water is $250 \mathrm{mg} / \mathrm{dm}^{3}$, which exceeds the permissible norms by several tens of times [20].

At the initial stages of field development, ignoring the swelling of the clay component of the reservoir and its dispersion, due to interaction with poorly prepared waters of low salinity, can lead to a decrease in the total volume of pore channels. And this, in turn, blocks the filtration of fluids in the porous medium and leads to pinching part of the oil reserves in the form of formed pillars. As a result, high values of residual oil saturation appear and, consequently, low current and final oil recovery factors.

The presented ability of clays should be regulated de- pending on the stage of development due to the competent choice of both the composition of the injected water and its salinity, as well as the selection of chemical reagents to optimize the process of displacing oil by water, acting as either inhibitors or catalysts of this process [21]. An equally important issue is the lack of proper attention to the surface molecular properties of reservoir rocks, such as wettability and capillary pressure when designing waterflooding. The first of them determine the direction of action of capillary forces, and the last one is the main force of resistance to the filtration of fluids in a porous medium. In a hydrophilic reservoir, it is energetically more favorable for oil to occupy relatively large pores, and for water, small ones; in a hydrophobic reservoir, vice versa. The widespread introduction of waterflooding at the initial stages of development, without taking into account the nature of wettability, led to the fact that in fields where the reservoir was predominantly hydrophobic, the pressure maintenance systems slightly affected oil recovery and led to sharp water cut due to uneven contraction of the oil-bearing contour during development, for example [22]. Also, studies [23-25] have shown that for low-permeability polymictic reservoirs it is more advantageous for the character of wettability to be initially hydrophilic. And in this case, the process of displacing oil from a porous medium is as close as possible to a piston.

Traditionally, it was believed that to ensure the cost-effective development of low-permeable reservoirs, it is necessary to commission the reservoir pressure maintenance system no later than the end of its second year. At the same time, there was no discussion about the operation of objects in the natural elastic-water-drive even at the initial stage. Several related studies have been carried out on this topic, including in the enhanced oil recovery laboratories of the Mining University [26-,32].

\section{Existing approaches to the design of field development and solving problems of organizing their waterflooding}

As a result of the analysis of the geological and technological features of the development of low-permeable polymictic reservoirs, it is possible to determine the differences between the approaches to the design of low-permeable polymictic reservoirs in comparison with the classical (Table 1). Also, Table 1 shows a summary characteristic of taking into account the features of the reservoirs under consideration and the problems that arise during the organization of their waterflooding.

Thus, it can be seen that the presented features and surface-molecular properties, as a rule, are not taken into account when designing the development of low-permeability polymictic reservoirs, and the solution of emerging problems is associated with certain difficulties. This means that the most optimal, easy-to-implement, and an expedient option for improving artificial waterflooding systems for low-permeable polymictic reservoirs is not 
Table 1: Comparison of approaches between the design of the development of classical and low-permeable polymictic reservoirs [33, with changes by the authors]

\begin{tabular}{|c|c|c|}
\hline Criterion & Classic design & $\begin{array}{c}\text { Designing the development of } \\
\text { low-permeability polymictic reservoirs }\end{array}$ \\
\hline $\begin{array}{c}\text { Reservoir properties and } \\
\text { heterogeneity }\end{array}$ & $\begin{array}{c}\text { Medium to high reservoir properties, } \\
\text { moderate heterogeneity }\end{array}$ & $\begin{array}{c}\text { Low reservoir properties, high } \\
\text { heterogeneity and discontinuity }\end{array}$ \\
\hline The nature of fluid filtration & Linear (Darcy's Law) & Non-linear effects are possible \\
\hline Development technologies & Traditional & $\begin{array}{c}\text { Intensive with maximum involvement of } \\
\text { reserves in development }\end{array}$ \\
\hline $\begin{array}{c}\text { Accounting for surface } \\
\text { molecular properties }\end{array}$ & Not provided & Not provided \\
\hline
\end{tabular}

solving the problems presented separately for each of the development objects, but considering a fundamentally new approach that allows them to be solved in relation to all of them. This way is the revision of the current waterflooding strategies.

Thus, it can be seen that the presented features and surface-molecular properties, as a rule, are not taken into account when designing the development of low-permeability polymictic reservoirs, and the solution of emerging problems is associated with certain difficulties. This means that the most optimal, easy-to-implement, and an expedient option for improving artificial waterflooding systems for low-permeable polymictic reservoirs is not solving the problems presented separately for each of the development objects, but considering a fundamentally new approach that allows them to be solved in relation to all of them. This way is the revision of the current waterflooding strategies.

\section{RESEARCH METHODS}

The aim of the research was to increase the efficiency of the development of oil fields with low-permeable polymictic reservoirs by improving the technology of artificial waterflooding. This goal is being realized by identifying the features of the development of low-permeable poly- mictic reservoirs of fields in Western Siberia and creating a strategy to improve the technology of artificial waterflooding, taking into account the impact on the surface molecular properties of the reservoir system in accordance with the stages of their development.

The developed strategy was substantiated step by step using hydrodynamic modeling using the Navigator software package for creating and calculating oil and gas field models from Rock Flow Dynamics. The calculation at all stages is realized within the framework of the model of two-phase filtration of immiscible fluids in a three-dimensional formulation using the example of a geological model of a section of a real field in Western Siberia, the productive layer of which is confined to the Jurassic deposits. The main parameters included in the geological and hydrodynamic model are presented in the table 2 .

In the area under consideration, the license holder has designed an uneven placement of 18 wells (Fig. 1, 2) with an average distance between wells equal to $650 \mathrm{~m}$. certain development time will be transferred to injection. At the same time, it is assumed that wells in low-lying areas in relation to the structure (numbered 10-18) with the course of certain development time will be transferred to injection.

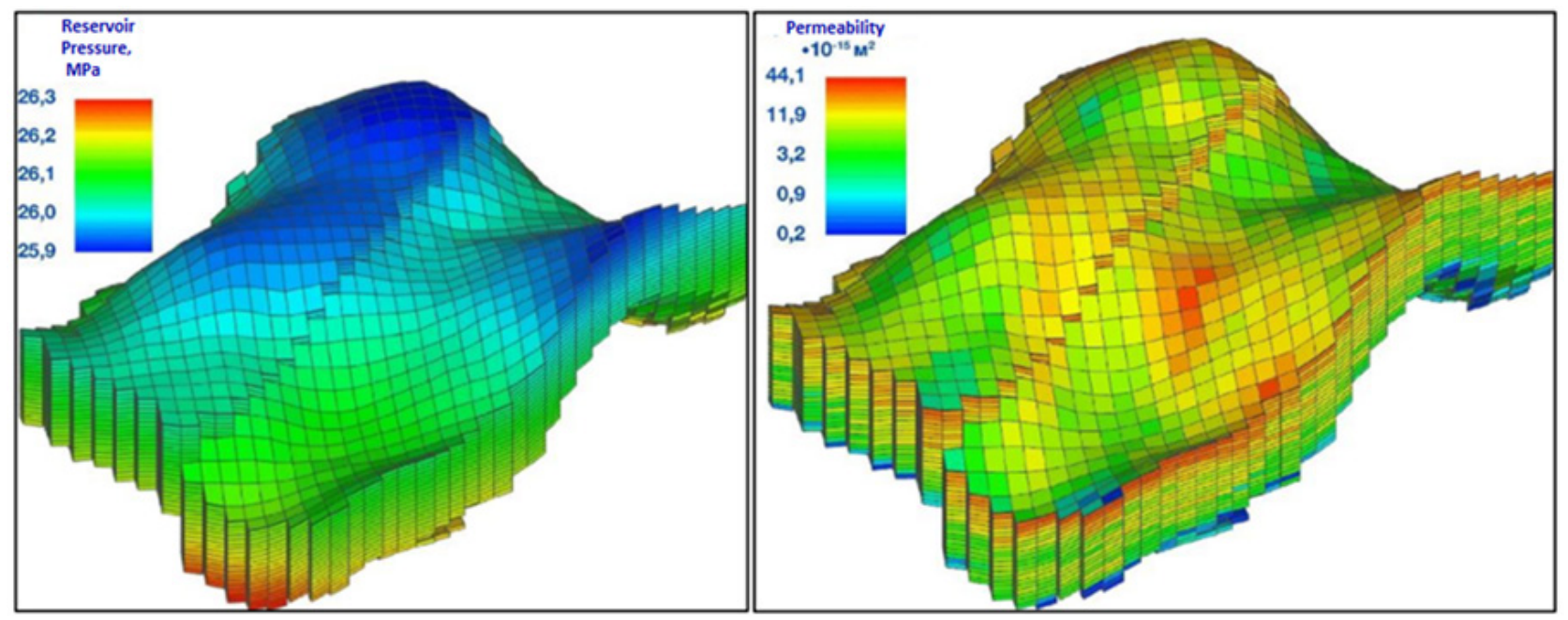

Figure 1: Geological and hydrodynamic model of the field area: on the left - 3D-map of the distribution of the initial reservoir pressure (in $\mathrm{MPa}$ ); on the right - 3D map of formation permeability distribution (in 10-15 $\mathrm{m}^{2}$ ) 
Table 2: The main parameters of the geological and hydrodynamic model

\begin{tabular}{|c|c|}
\hline Parameter & Value \\
\hline \multicolumn{2}{|c|}{ Simulation area parameters } \\
\hline Number of cells in the modeling area & $40 \times 31 \times 21$ \\
\hline Sizes of cells of the grid area, $\mathrm{m}$ & $100 \times 100 \times 1$ \\
\hline \multicolumn{2}{|c|}{ Reservoir parameters } \\
\hline Initial reservoir pressure, $\mathrm{MPa}$ & 26 \\
\hline Average porosity, unit fraction & 0,16 \\
\hline Maximum permeability, $10-15 \mathrm{~m}^{2}$ & 44,15 \\
\hline Average permeability, $10-15 \mathrm{~m}^{2}$ & 13,44 \\
\hline Minimum permeability, $10-15 \mathrm{~m}^{2}$ & 0,23 \\
\hline Average initial oil saturation, unit fraction & 0,57 \\
\hline Average initial water saturation, unit fraction & 0,43 \\
\hline Mass oil reserves, thousand tons & 8951,4 \\
\hline \multicolumn{2}{|c|}{ Reservoir fluid parameters } \\
\hline Density of oil in reservoir conditions, $\mathrm{kg} / \mathrm{m}^{3}$ & 787 \\
\hline Density of water in reservoir conditions, $\mathrm{kg} / \mathrm{m}^{3}$ & 1022 \\
\hline Volumetric coefficient of oil, units & 1,14 \\
\hline Oil viscosity in reservoir conditions, $\mathrm{mPa} \cdot \mathrm{s}$ & 0,3 \\
\hline Water viscosity at reservoir conditions, $\mathrm{mPa} \cdot \mathrm{s}$ & 1 \\
\hline Average bubble-point pressure, $\mathrm{MPa}$ & 10 \\
\hline \multicolumn{2}{|c|}{ Well operation and configuration parameters } \\
\hline Well completion system & directional wells \\
\hline Controlled parameter of production wells operation & Bottomhole pressure \\
\hline Controlled parameter of injection wells operation & Bottomhole pressure \\
\hline $\begin{array}{l}\text { Restriction of the operating mode of the production } \\
\text { well, } \mathrm{MPa}\end{array}$ & 10 \\
\hline $\begin{array}{l}\text { Restriction of the operating mode of the injection well, } \\
\qquad \mathrm{MPa}\end{array}$ & 40 \\
\hline
\end{tabular}

All calculations were carried out until the shutdown of all production wells in the area under consideration. A condition for stopping oil production from a well is to achieve a water cut level of the produced product corresponding to 0.98 units.)

Limitations on the operating modes of injection and production wells are imposed based on the threshold values of the bottomhole injection pressure. This is the pressure at which fracture occurs in the reservoir, i.e. the effect of auto-hydraulic fracturing (hydraulic fracturing) is excluded, and the pressure of oil saturation with gas, i.e. the effect of degassing and the appearance of the third phase in reservoir conditions is not allowed. All processes occurring in the reservoir system, when oil is displaced by various injected agents, are taken into account in the model due to changes in the curves of relative phase permeabilities (Fig. 3), constructed according to existing research in the scientific literature [34-39], as well as due to the previously mentioned effects of changing the reservoir properties (reservoir properties) of the reservoir system, in particular, permeability.

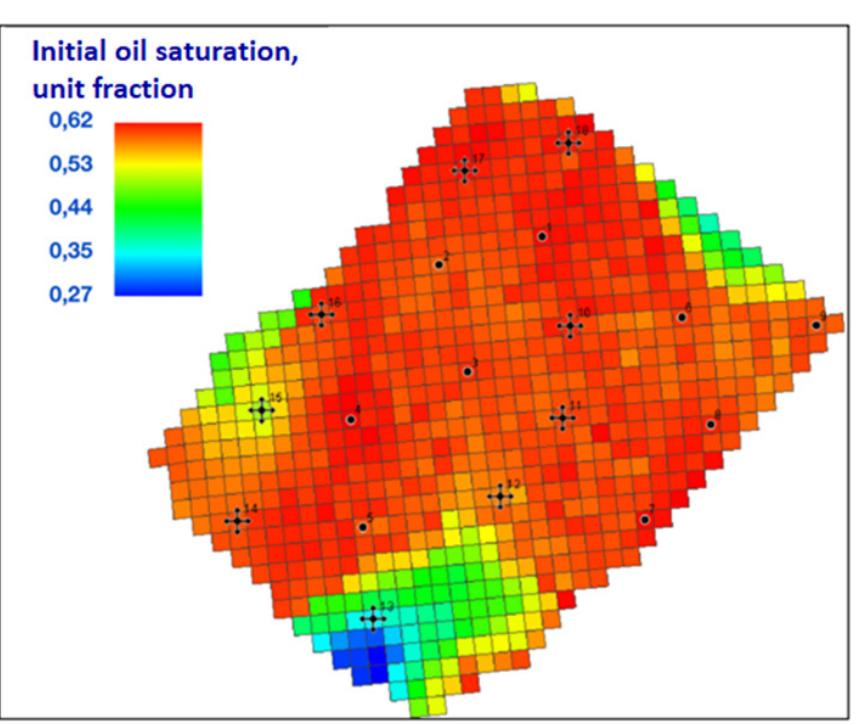

Figure 2: The placement of wells projected by the license holder at the field on the 2D map of the distribution of the initial oil saturation of the reservoir (in unit fractions) 


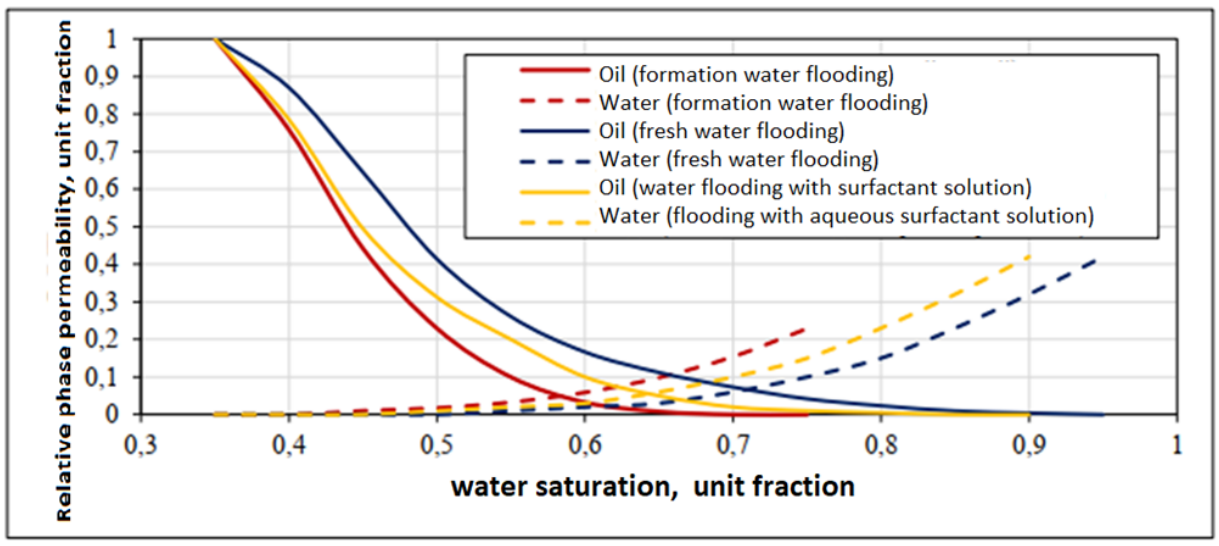

Figure 3: The curves of relative phase permeabilities used in the model

\section{RESULTS}

Summarizing the information presented before, it can be stated that the optimal strategy for flooding of the low-permeable polymictic reservoirs can be presented by the next stages:

1. Study of the predominant nature of wettability of reservoir rocks and capillary effects at the exploration stage and design of selective well pattern;

2. If there is a hydrophilic porous medium it's necessary to organize a reservoir pressure maintenance system using an aqueous solution of surfactants as the injection agent, the composition of which is aimed at reducing the degree of hydration of clay minerals and the interfacial tension at the boundary of the displacing-displaced fluid. If there is a hydrophobic wettability of a porous medium, the composition must be selected in such a way that local hydrophilization of the rock occurs, taking into account the presence of other previously indicated effects. Then we recommend organizing the water flooding system during the optimal period of pre-emptive water injection into the productive reservoir, which is determined for each individual field development system;

3. When launching the production wells it's necessary to organize the transition to highly mineralized water that fully coincides with the reservoir water in composition and physical and chemical properties;

4. As the water content of the produced fluid increases, gradually switch to pumping a mixture of reservoir or produced water, without changing the salt composition, with fresh water in order to redistribute filtration flows in the reservoir medium and reduce the permeability of highly permeable washed channels by stimulating clay swelling;

5. When the water cut of the produced fluid reaches above $80-85 \%$, which is confirmed by the results of laboratory experiments [40] (it is recommended to consider $60 \%$ as the boundary value for the reservoir AC10-12 by authors [41-43]), switch to pumping fresh water with the possibility of adding surfactants to displace residual oil reserves in areas not covered by the development process.
In the course of previous theoretical studies, as well as hydrodynamic simulation, it was found that the initial conditions for oil displacement from a porous medium are important for the implementation of advanced flooding system. In this regard, the next step for justifying the developed strategy is to compare the options that imply the injection of the following agents during the optimal pre-injection period (1 month):

\section{Reservoir water;}

2. An aqueous solution consisting of non-ionic surfactant and cationic surfactant at a concentration of $0.05 \%$ and $0.1 \%$ by weight, respectively;

3. Fresh water.

In the case of the first option, which is considered as the basic one, according to previously presented studies, despite their greatest compatibility with reservoir conditions, there is still a slight deterioration in absolute permeability due to hydration of clay minerals. Since the characteristics of this process depend on many parameters, in particular the structure of the pore medium and in particular the content of kaolinite, we take the coefficient 1.1 as the value of reducing the absolute permeability [27].

The interfacial tension decreases at the boundary "displacing and displaced fluid" when an aqueous solution of the surfactant composition is injected into the reservoir. Then the optimal displacement conditions are formed by preventing the swelling of clay minerals, as well as changing the nature of the reservoir wettability in the area of injection wells from predominantly hydrophobic to neutral. In the case of fresh water injection at the initial stage, only the deterioration of reservoir properties in the area of injection wells was taken into account due to a reduction in the size of pore filtration channels, expressed in a twice decrease in permeability according to the results of studies [35].

The transition to water that is fully compatible with the reservoir one is further considered after preliminary injection of the considered injection agents for all options. Based on the analysis, the results obtained for a single-row system are the most representative in relation to advanced flooding. Therefore, hydrodynamic simulating for the section of the reservoir which is under consider- 


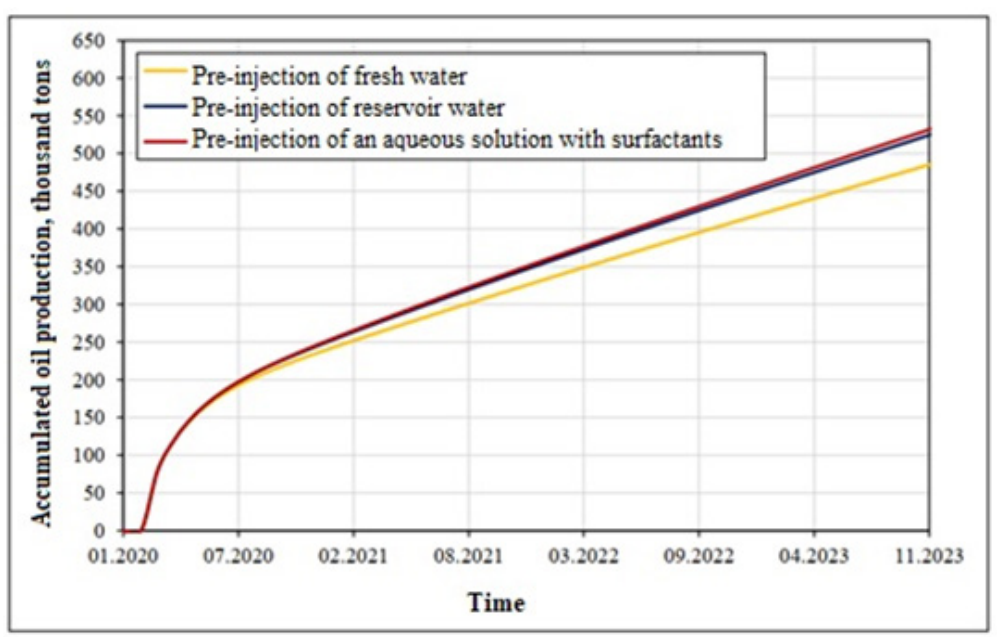

Figure 4: Dynamics of accumulated oil production for advanced flooding by different injection agents

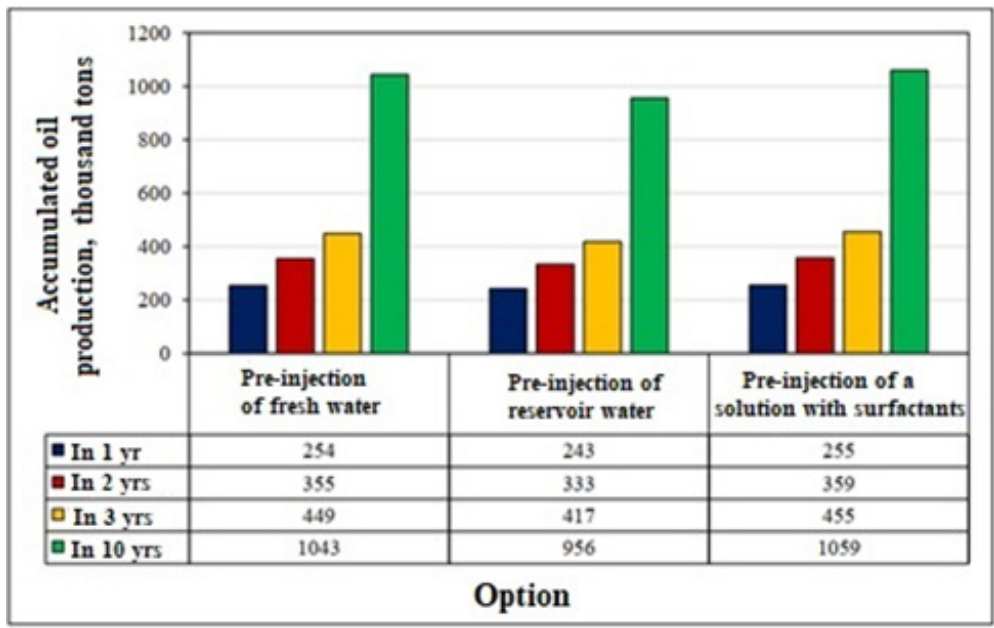

Figure 5: Results of calculations for evaluating the effectiveness of advanced flooding by different injection agents (accumulated oil production)

ation will be carried out on the basis of this well pattern. Other parameters remain unchanged. The calculation results are shown in Fig. 4 and 5.

It becomes obvious, according to the presented graphs, that not only the organization of advanced flooding itself ensures the greatest changes in the technological parameters of the reservoir development at the initial stages (during the first year), but also the type and quality of preparation of the injected agent also ensures their further advantages. At the same time, any deterioration in filtration conditions during pre-emptive water injection, even if the most suitable injection agent is selected, but not in best conditions, negatively affects the further reservoir development, which is especially clearly monitored after pumping fresh water, even though the permeability is partially restored after switching to reservoir water.

The slight excess of the schedule by accumulated oil production during the injection of an aqueous solution of surfactants is mainly due to the fact that the adsorption of their molecules on clay minerals prevents their swelling and ensures the maximum possible preservation of the original reservoir properties. The effectiveness of implementing advanced flooding, taking into account the careful selection of the injection agent, can be traced already during the first year, since at this stage the excess of accumulated oil production compared to other options is 1,633 and 12,032 thousand tons, which in relative terms corresponds to 0.6 and $4.7 \%$. In the future, all other things being equal, the difference between these technological indicators only increases.

Thus, the first stages of the developed strategy for the initial stage of development can be recommended for consideration when designing for each specific field or its individual section with low-permeable polymictic reservoirs.

\section{Evaluation of the effectiveness of implementing low-mineralized flooding system at the final stage of development of low-permeable polymictic reservoirs}

The logical conclusion of assessing the feasibility of implementing the developed strategy for improving artificial flooding systems for low-permeable polymictic reservoirs is to evaluate the effectiveness of using fresh water at a final stage of development. It is carried out in two stages: 
1. Comparison of technological indicators of the development of the considered field section during the transition from pumping of the reservoir water to fresh water for various time periods corresponding to the achieved values of water cut of the produced fluid.

2. Comparison of the traditional approach, which implies the using of injection wells for producing of oil and their further start-up for pumping water compatible with the reservoir, before the wells are decommissioned, and the optimal developed strategy for the considered field section.

In the first case calculations were made as a sequel to the initial option of the developed strategy, i.e. pre-emptive injection of surfactant for 1 month and the subsequent transition to the injection of reservoir water, and further responsive to the changing of the relative permeability for filtrable phase in the direction of hydrophilization of rocks after transition to fresh water for three values of water cut crude production, selected according to the previously conducted analysis, i.e. at 60,80 and $85 \%$, respectively. The consideration of previously studied mechanisms through the relative permeability is due to the fact that the previously presented processes of intermolecular interaction are very complex in nature and cannot be described by any of the currently existing hydrodynamic simulators, and is confirmed by the international experience of simulating [44-47]. Since the beginning of flooding corresponds to previously implemented options, the dynamics of the technological indicators of interest in the development of the considered field section, in particular the accumulated oil production fully coincides with them. Therefore, only the final figures at the end of oil production were estimated. The results of the implemented calculations of the first stage are presented in table 3.

It is obvious that under the set conditions in the hydrodynamic model, the best option for accumulated oil production will be achieved with a lower water cut of the produced fluid. However, if we evaluate the final oil recovery factor, the difference between the considered options under the given conditions is no more than $0.8 \%$. At the same time, if the resulting difference in accumulated oil production by the end of development of the considered field section is distributed in relation to the time for which it is formed, then the growth rate will be equal to 54 tons per year per production well. According to the authors, taking into account the real conditions of field development with the low-permeable polymictic reservoir, where the early transition to fresh water, in addition to the redistribution of filtration flows and involvement in impact uncovered reserves, it may lead to a substantial reduction of reservoir properties and to provide received a relatively low growth rate of cumulative production in such a large area. In this regard, the best option is to start pumping fresh water at water cut values in the range from 80 to $85 \%$, as recommended in one of the studies.

The second stage involved comparing previously obtained results for two strategies, which are described in detail in the table. 4 . The increase in oil recovery factor relative to the basic strategy under the set conditions at the end of the development of the reservoir is $11.3 \%$, which generally corresponds to the results obtained after the implementation of low-mineralized flooding in terrigenous reservoirs.

The nature of oil production following the implementation of the defined strategies can be monitored on the basis of the distribution of residual oil saturation (see Fig. 6).

\section{ANALYSIS OF RESULTS}

The results obtained in this work lead us to the following conclusions.

1. Authors revealed features of development and problems of flooding organization for low-permeable polymictic reservoirs on the example of oil fields confined to the Jurassic sediments. As the main way to improve the efficiency of their development, a recommendation is put forward to review existing flooding strategies, taking into account the impact on the surface-molecular properties of the reservoir system.

2. Based on the studied theoretical and practical studies, a strategy was proposed for improving artificial flooding systems for low-permeable polymictic reservoirs, which implies a point effect on the surface-molecular properties of the reservoir system in accordance with the stages of field development. It includes recommendations on the choice of the injected agent in the reservoir pressure maintenance

Table 3: Technological indicators of the development of the considered field section during the transition to fresh water injection for different values of water cut of the produced fluid

\begin{tabular}{|c|c|c|c|c|}
\hline Option's number & $\begin{array}{c}\text { Water cut of the produced } \\
\text { fluid during the transition } \\
\text { to fresh water injection, \% }\end{array}$ & $\begin{array}{c}\text { Time interval for } \\
\text { reaching the set } \\
\text { water cut, } \\
\text { Years }\end{array}$ & $\begin{array}{c}\text { Accumulated oil production } \\
\text { by the end of development } \\
\text { of the reservoir, } \\
\text { thousand tons }\end{array}$ & $\begin{array}{c}\text { Final oil recovery } \\
\text { factor, units }\end{array}$ \\
\hline 1 & 60 & 46 & 4548,4 & 0,512 \\
\hline 2 & 80 & 65 & 4524,5 & 0,505 \\
\hline 3 & 85 & 76 & 4508,5 & 0,504 \\
\hline
\end{tabular}


Table 4: Comparison of the technological indicators at the developed and basic flooding strategies

\begin{tabular}{|c|c|c|c|c|}
\hline Strategy & $\begin{array}{l}\text { Description of } \\
\text { strategy }\end{array}$ & The injected agent & $\begin{array}{l}\text { Accumulated oil production } \\
\text { by the end of reservoir de- } \\
\text { velopment, thousand tons }\end{array}$ & $\begin{array}{l}\text { Final oil recovery } \\
\text { factor, units }\end{array}$ \\
\hline Basic & $\begin{array}{l}\text { Using of the injection } \\
\text { wells for oil production } \\
\text { for } 1 \text { month and sub- } \\
\text { sequent simultaneous } \\
\text { injection and production } \\
\text { of fluids }\end{array}$ & $\begin{array}{c}\text { Reservoir water - for the } \\
\text { whole period of reservoir } \\
\text { development }\end{array}$ & 3511,8 & 0,392 \\
\hline \multirow{3}{*}{ Developed } & \multirow{3}{*}{$\begin{array}{c}\text { Advanced flooding for } 1 \\
\text { month with subsequent } \\
\text { commissioning of pro- } \\
\text { duction wells }\end{array}$} & $\begin{array}{l}\text { Aqueous solution of the } \\
\text { surfactant composition } \\
\text { for the period of the } \\
\text { pre-emptive injection }\end{array}$ & \multirow{3}{*}{4508,5} & \multirow{3}{*}{0,505} \\
\hline & & $\begin{array}{l}\text { Until the water cut of the } \\
\text { produced fluid reaches } \\
85 \% \text { - reservoir water }\end{array}$ & & \\
\hline & & $\begin{array}{c}\text { After reaching the water } \\
\text { cut of the produced fluid } \\
\text { a value of } 85 \% \text { - fresh } \\
\text { water }\end{array}$ & & \\
\hline
\end{tabular}

system and describes the main mechanisms of their action.

The strategy consists of several stages and has the following goals:

- at the initial stage of field development during flooding, it is necessary to preserve the initial conditions of fluid filtration as much as possible, to ensure a high-quality relationship between production and injection wells, as well as a uniform development of oil reserves. Achievement of the presented conditions is provided by the organization of pre-emptive injection of a low-concentrated aqueous solution of surfactants into the reservoir, including non-ionic and cationic surfactants, designed for the period under review not only to ensure the accumulation and subsequent rational use of the elastic reservoir reserve, but also to reduce the probability of deterioration of its reservoir properties and the manifestation of nonlinear filtration effects in the area of injection wells.

- taking into account the commissioning of production wells, the main task is to maintain the conditions of oil displacement achieved at the previous stage, as well as rational cost management. Due to the low economic effect achieved in most cases in a field practice from the use of solutions of low-concentration surfactant throughout the reservoir development, the most optimal is the transition to the injection of highly mineralized water that maximally corresponds to reservoir conditions. The main sources of water supply can be the waters of the Aptian-Albian-Cenomanian or Jurassic hydrogeological sediments. In case of insufficient volume of water for the needs of the main- tenance system, and also to control the properties of the reservoir system and the economically efficient use of water resources is required as an additional source of water to consider water Oligocene-Quaternary hydrogeological sediments, which is fresh, and to provide for the possibility of their mixing with water the main sources including the growth of the water cut of the produced fluid.

- at the final stages of field development during flooding, it is advisable to ensure the involvement of oil reserves that are not covered by the development process. Taking into account the previous stage, the

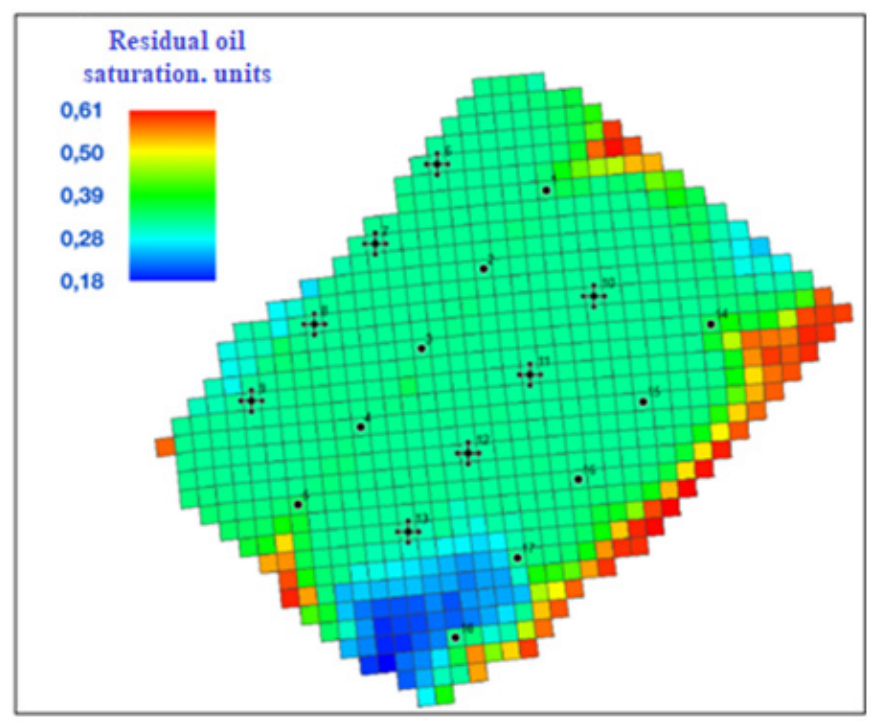

Figure 6: Distribution of residual oil saturation (in units) after the implementation of set flooding strategies 
transition to flooding with completely fresh water is the most appropriate, as a result of which, due to the redistribution of filtration flows and the final hydrophilization of the reservoir medium surface, the residual oil saturation after the previous flooding transition will be reduced.

3. In order to obtain more accurate results that are necessary for the design of the presented strategy within specific fields whose oil reserves are confined to the Jurassic sediments, as well as its further improvement, the directions of further research are outlined. The results of a preliminary assessment of its effectiveness allow us to recommend it for consideration as one of the options for their development. At the same time, for newly commissioned fields, as well as those with a long history of development, after laboratory studies, it is necessary to select sites for the implementation of pilot industrial tests for the first two stages and fresh water injection.

\section{AUTHORS' CONTRIBUTION}

Palyanitsina Aleksandra, PhD - analysis and identification of geological and technological features of the development of low-permeable polymictic reservoirs. Development of a strategy for improving the technology of artificial flooding of the low-permeable polymictic reservoirs.

Tananykhin Dmitry, PhD - evaluation of the effectiveness of implementing low-mineralized flooding at the final stage of development of low-permeable polymictic reservoirs.

Masoud Riazi, PhD - assessment of the feasibility of transiting to fresh water injection for different water cut values of the produced fluid.

\section{REFERENCES}

1. Prischepa, O. M., Nefedov, Y. V., \& Kochneva, O. E. (2020). Raw material base of hard-to-extract oil reserves of russia. [Materia-prima base de reservas de oleo de difícil extracao da Russia] Periodico Tche Quimica, 17(34), 915-924.

2. Rogachev M.K., Mukhametshin V.V., Kuleshova L.S. (2019). Improving the efficiency of using the resource base of liquid hydrocarbons in the Jurassic sediments of Western Siberia. Notes of the Mining Institute. Vol. 240.

3. Korolev, M., Rogachev, M., \& Tananykhin, D. (2020). Regulation of filtration characteristics of highly watered terrigenous formations using complex chemical compositions based on surfactants. Journal of Applied Engineering Science, 2020, vol. 18, br. 1, str. 147-156 doi:10.5937/jaes18-24542
4. Sabukevich, V.S., Podoprigora, D.G., \& Shagiakhmetov, A.M. (2020). Rationale for selection of an oil field optimal development system in the eastern part of the pechora sea and its calculation. Periodico Tche Quimica, 17(34), 634-655.

5. Khavkin A.Ya. (2010). Nanophenomena and nanotechnologies in oil and gas production. - Izhevsk: SRC "Regular and chaotic dynamics", Institute of computer science, 2010 - p. 692

6. Sidorovsky V.A. (1978). Opening of layers and increasing the productivity of wells. M.: Nedra, 1978. $-256 \mathrm{p}$.

7. Shpurov I.V. (2015). Scientific and methodological substantiation of effective development of hard-to-recover oil reserves in the Jurassic sediments of Western Siberia based on detailed geological and technological modeling: dis.... doctor of technical Sciences: 25.00.17 / Igor Viktorovich Shpurov. - Tyumen, 357 p.

8. Dobrynin V.M., Mulin V.B., Kulikov B.I. (1973). Irreversible decrease in the permeability of polymictic sandstones of the Samotlor reservoir. Oil industry, 1973, \#10, p. 34-37.

9. Sokolov V.N. (1996). Microcosm of clay rocks. Sorovsky educational journal, 1996, \# 3, p. 56-64

10. Kravchenko I.I. (1971). Adsorption of surfactants in the process of oil production /I.I. Kravchenko, G.A. Babalyan. - M.: Nedra, 1971. - 159 p.

11. Kolpakov V.V., Zholudeva V. A., \& Saitgaleev J.H. (2017). Increase the efficiency of exploration activities and reducing development risks on the basis of litho-technological modeling of shale reservoir U1 Kogalym area. Oilfield business. \#10. - p. 9-13.

12. Baykov V.A., Galeev R.R., \& Kolonskikh A.V. (2013). Nonlinear filtration in low-permeability reservoirs. Analysis and interpretation of the results of laboratory studies of the core of the Priobskoye field. Scientific and technical Bulletin of Rosneft". \#2. - p. 8-12.

13. Baykov V.A., Galeev R.R, Kolonskikh A.V. (2013). Nonlinear filtration in low-permeable reservoirs. Influence on technological indicators of field development. Scientific and technical Bulletin of Rosneft". \#2. - p. 17-19.

14. Baykov V.A., Kolonskikh A.V., Makatrov A.K. [et al.] (2013). Nonlinear filtration in low-permeable reservoirs. Laboratory filtration studies of the core of the Priobskoye oilfield. Scientific and technical Bulletin of Rosneft". \#2. - p. 4-7. 
15. Grachev S.I., Korotenko V.A., Kushakova N.P. (2020). Investigation of the effect of two-phase filtration transformation on the formation of zones of uncovered oil reserves, Notes of the Mining Institute, 241, p. 68. DOI: 10.31897/pmi. 2020. 1. 68.

16. Palyanitsina, A., \& Sukhikh, A. (2020). Peculiarities of assessing the reservoir properties of clayish reservoirs depending on the water of reservoir pressure maintenance system properties. Journal of Applied Engineering Science, 2020, vol. 18, br. 1, str. 10-14 doi:10.5937/jaes18-24544

17. Belonogov E.V., Pustovskikh A.A., Sitnikov A.N. (2018). Criterion for selecting a method for developing low-permeable reservoirs. PRONEFT. Professionally about oil.

18. STP 0148463-007-88. Temporary standards for the content of suspended solids and petroleum products in water used in reservoir pressure maintenance systems $--6 \mathrm{p}$.

19. OST 39-225-88. Water for flooding oil reservoirs. Quality requirements. - Acts. 01.07.90. - Moscow: publishing house of standards.

20. Supplement to the technological scheme for the development of the Untyge oil field", JSC Tyumenniiproekt, Tyumen, 2012.

21. Zheltov J.V., Stupochenko V.E., Havkin A.Y. (1981). About the features of flooding of oil reservoirs with clay-containing reservoirs. Metanoeite.. \#7. - p. 4247.

22. Bol'shakov Yu.Ya. (2002). Using data about capillary pressures for oil recovery by waterflooding reservoirs in the fields of Western Siberia/ Y. Bolshakov, V.M. Matusevich, T.V. Semenova. Oil and gas. No.1. - p. 10-14

23. Akhmetshin M.A. (2016). About artificial hydrophobic rocks of bottom-hole zone of producing wells. Oil industry. No. 1. - p. 73-77.

24. Kanzafarov F.Ya. (2011). Changing the properties of reservoir systems in the operation of oil fields. Saint Petersburg: Nedra, 303 p.

25. Struchkov I. A., \& Rogachev M. K. (2017). Wax precipitation in multicomponent hydrocarbon system. Journal of petroleum exploration and production technology. Vol. 7 (2). - p. 543-553.

26. Bagautdinov A.K. \& Efremov I.F. (1985). Experience in designing and developing low-permeable reservoirs of Jurassic sediments. Oil industry. No. 8. - p. 3-10.

27. Kuznetsova A.N., Zykova V.E., \& Logashova D.S. (2016). Improvement of reservoir pressure maintenance system in conditions of low-permeable polymictic reservoirs in Western Siberia. Ashirov readings. Vol. 2. - No. 1-1(8). - p. 7-12.
28. Rogachev M.K., \& Mukhametshin V.V. (2018). Control and regulation of the process of hydrochloric acid impact on the bottom-hole zone of wells based on geological and field data. Notes of the Mining Institute. Vol. 231.

29. Sandyga, M. S., Struchkov, I. A., \& Rogachev, M. K. (2020). Formation damage induced by wax deposition: Laboratory investigations and modeling. Journal of Petroleum Exploration and Production Technology, 10(6), 2541-2558. doi:10.1007/s13202020-00924-2.

30. Khaibullina, K.S., Sagirova, L.R., \& Sandyga, M.S. (2020). Substantiation and selection of an inhibitor for preventing the formation of asphalt-resin-paraffin deposits. Periodico Tche Quimica, 17(34), 541-551.

31. Morenov, V., \& Leusheva, E. (2017). Development of drilling mud solution for drilling in hard rocks. International Journal of Engineering, Transactions A: Basics 30(4), p. 620-626. DOI: 10.5829/idosi. ije.2017.30.04a.22

32. Rogov E A. (2020). Study of the permeability of the bottom-hole zone of wells under the influence of process fluids. Notes of the Mining Institute, 242, p. 169. DOI: 10.31897/pmi. 2020. 2. 169.

33. Shupik N.V. (2017). Improving the efficiency of areal flooding systems for low-permeable reservoirs in Western Siberia: dis. ... candidate of technical Sciences:25.00.17 / Shupik Natalia Vladislavovna. Moscow, 2017. - 114 p.

34. Sintsov I.A., Kovalev I.A., Evdokimova A.S., \& Fakhretdinova G.M. (2016). Creating a universal hydrodynamic model of upper Jurassic sediments within the Nizhnevartovsk arch. Advances in modern natural science. No. 2. - p. 177-181.

35. Kuznetsova A.N. (2018). Justification of technology for flooding low-permeable polymictic reservoirs using surfactants: dis. ... candidate of technical Sciences: 25.00.17 / Kuznetsova Alexandra Nikolaevna. Saint Petersburg, 2018. - 113 p.

36. Akhmetgareev V.V. (2016). Research of processes of development of oil reservoirs by low-mineralized flooding on the basis of modeling (on the example of fields of the Republic of Tatarstan): candidate of technical Sciences: 25.00.17 / Vadim V. Akhmetgareev. - Bugulma, 2016. - 136 p. 
37. Turgazinov I.K. (2018). Improving the efficiency of development of oil fields that are in the final stages of operation with the use of low-mineralized flooding (on the example of South Turgay fields): dis.... Dr Phil: 6D070800 / nurgazinov of Elias Kazbeguri. - Almaty, 2018. - $111 \mathrm{p}$.

38. Lalomov, D. A. and Glazunov, V. V. (2018). Estimation of the filtration coefficient of sandy-clay soils based on a joint interpretation of data from resistance and geo-radar methods, Notes of the Mining Institute, 229, p. 3.DOI: 10.25515/pmi.2018.1. 3.

39. Ermekov, R. I., Merkulov, V. P., Chernova, O. S. and Korovin, M. O. (2020). Features of accounting for permeability anisotropy in the hydrodynamic model, Notes of the Mining Institute, 243, p. 299. DOI: 10.31897/pmi. 2020. 0. 299.

40. Igdavletova M. (2015). Influence of mineralization of injected water on permeability and oil recovery factor. Neftegaz.RU. URL:https://neftegaz.ru/science/ development/331660-vliyanie-mineralizatsii-zakachivaemoyvody-na-pronitsaemost-i-nefteotdachu-kollektorov/ (accessed: 04.01.2020).

41. Mashorin V.A. (2015). Research and development of technology for increasing the coefficient of oil displacement by water of different mineralization: dis. ... candidate of technical Sciences: 25.00.17 / Mashorin Vladimir Aleksandrovich. - Tyumen, 2015. - 94 p.

42. Updated project for the development of the Samotlor field: in 14 volumes / JSC "Tyumen oil research center", the company "Petro Alliance services company limited". - Tyumen-Moscow, 2005
43. Shpurov I.V., \& Tudvachev A.V. (2015). Justification of the boundary value of reservoir permeability during their differentiation into categories with high and low filtration potentials. Oil industry. \#9. - p. 7374.

44. Jerauld G. R., Webb K. J., Lin C. Y., \& Seccombe J. (2006). Modelling low-salinity waterflooding. SPE Annual Technical Conference and Exhibition. 13 p.

45. Skrypchuk, P., Zhukovskyy, V., Shpak, H., Zhukovska, N., \& Krupko, H. (2020). Applied aspects of humus balance modelling in the rivne region of ukraine. Journal of Ecological Engineering, 21(6), 42-52. doi:10.12911/22998993/123255

46. Yemelyanov, V. A., Yemelyanova, N. Y., Nedelkin, A. A., Glebov, N. B., \& Tyapkin, D. A. (2019). Information system to determine the transported liquid iron weight. Paper presented at the Proceedings of the 2019 IEEE Conference of Russian Young Researchers in Electrical and Electronic Engineering, EIConRus 2019, 377-380. doi:10.1109/EIConRus.2019.8656693

47. Zhukovskyy, V., Zhukovska, N., Vlasyuk, A., \& Safonyk, A. (2019). Method of forensic analysis for compromising carrier-lock algorithm on 36 modem firmware. Paper presented at the 2019 IEEE 2nd Ukraine Conference on Electrical and Computer Engineering, UKRCON 2019 - Proceedings, 11791182. doi:10.1109/UKRCON.2019.8879941 